\title{
DETERMINANTS OF FOREIGN DIRECT INVESTMENTS IN BRICS COUNTRIES: THE ROLE OF CARBON EMISSIONS
}

\author{
MURTALA ABDU $^{1 *}$, K. SELVASUNDARAM ${ }^{2}$ AND S. SAGATHEVAN ${ }^{3}$ \\ ${ }^{1}$ Department of Economics, SRM IST, Kattankullathur-603203, Chennai. ${ }^{2}$ Department of Corporate Secretaryship and \\ Accounting Finance, SRMIST, Kattankullathur-603203, Chennai. ${ }^{3}$ Department of Economics, Madras Christian College, \\ Tambaram East, Chennai- 600059.
}

*Corresponding author: ma5578@srmist.edu.in

Submitted final draft: 30 December 2020 Accepted: 9 January 2021

http://doi.org/10.46754/jssm.2021.10.022

\begin{abstract}
Using the panel data for BRICS countries from 1995 to 2018, this study empirically examines the carbon emissions (CO2) alongside the other traditional determinants of foreign direct investments (FDI). The Continuously Updated Fully Modified Estimator (CUP-FM) and Bootstrapped panel causality test were adopted for the estimation. The results from CUP-FM estimator revealed that the GDP, exchange rate and carbon emissions all have a positive and significant effect on FDI, while inflation is reported to be negatively related with FDI. This means that, apart from these traditional variables (i.e. GDP, EXC and CPI), CO2 is also an important determinant of FDI in the BRICS countries. The result from the causality test has shown a bidirectional causality between FDI and GDP, CPI and FDI, and also a onedirectional causality was found between FDI and EXC. However, no such causal relation was reported between FDI and CO2. This does not rule out the existence of causality between FDI and $\mathrm{CO} 2$ in at least some of the countries. We recommend that the designing of any FDI-incentive policy should take into account its environmental implications. More should be done in the generation of environmentally sustainable energy as the sustainability of the environment should always be given priority.
\end{abstract}

Keywords: CUP-FM, BRICS, carbon emissions, FDI, panel data.

\section{Introduction}

The vital role of FDI in the expansion of international trade cannot be overemphasised. Over the past decade, the global economy has witnessed an unprecedented upward trend in FDI (UNTAD, 2006). Thus, its role in terms of employment generation, economic growth and general welfare of the recipient countries has since been considered as enormous (Blomton, 1989; Ju \& Wei, 2007; Wolf, 2008). In recent years, FDI has become one of the dominant determinants of economic growth of developing and emerging economies. As a result, it will be critical for each country, particularly developing ones, to embark on the implementation of policy measures that will ensure significant inflows of foreign resources and remain firmly committed to its positive role in income and employment creation, as well as technical progress.

Many countries have prioritised FDI inflows and, as a result, have designed their regulatory and fiscal policies to encourage inward FDI flows. However, caution must be maintained, in that policymakers must ensure that every policy pursued do not yield sub-optimal results. Moreover, literature revealed that it is the resources and market seeking that mainly spur FDI in the first place (Knickerbocker, 1973; Buckley \& Casson, 1976; OECD, 2003). To that end, this study seeks to revisit the determinants of FDI in BRICS countries. Although several studies have been conducted on the same topic, ours slightly varies by trying to examine, among other things, by how much the amount of $\mathrm{CO} 2$ remitted affect the flow of FDI to these countries. We further attempt to study the causal effect among CO2, GDP, exchange rate, inflation and FDI.

BRICS are termed as the five leading world emerging economies and out of these countries, India and China are exceptional in terms of market size and are expected to control the world market in terms of supply of consumer goods and services in the very near future, while Russia and 
Brazil were predicted to be dominant in terms of supply of raw materials (Sachs et al., 2000).

The combined nominal GDP of BRICS stood at US\$18.6 trillion as at 2018, and this is equivalent to about $23.2 \%$ of the global GDP and around $\$ 40.55$ trillion or $32 \%$ of the Global GDP PPP, (International Monetary Fund (IMF), 2013). The higher GDP is associated with higher energy consumptions (Akram, 2020) and this, concurrently with the growing industrialisations and demographic issues, are expected to rise the amount of energy consumption among developing countries and BRICS. The energy consumptions of BRICS constitute about $40 \%$ of the total global energy consumption as at 2013 (Shahbaz, 2013), and it is expected to rise by not less than $40 \%$ by the year 2040 (Akram, 2020).

With energy demand all over the world are being ordinarily met by fossil fuel, this has led to energy consumption as a main source of carbon emissions (IEA, 2013). The global carbon emissions stood at 34.5 billion tonnes in 2012 and the total CO2 remitted by BRICS countries altogether reached $38 \%$ of the global greenhouse remittance in 2014 (Yilanci, 2019; Wang et al., 2020).

There have been massive campaigns to reduce the amount of $\mathrm{CO} 2$ emissions, and this resulted in the Kyoto protocol as contained in the agenda of United Nations Framework Convention on Climate Change (UNFCC). In line with this, a considerable number of countries have embarked on the development of renewable energy because of environmental sustainability (Yüksel et al., 2020). Thanks to the remarkable effort made by BRICS countries, all its members, except Russia, have made it to the top ten countries that spend hugely on renewable energy (Wang et al., 2020).

BRICS is the host of more than $15 \%$ of the total global FDI flow as at 2015 and it is the home of $9 \%$ of the total global FDI stock in the same year (UNCTAD, 2016). FDI is one of the strong contributors of greenhouse remittance and a few recent studies revealed its massive link to the amount of $\mathrm{CO} 2$ remitted in a country or set of countries (Essandoh et al., 2019; Do \& Dinh, 2020; Jiang et al., 2020; Mahmood et al., 2020; Mukhtarov et al., 2020; Nguyen et al., 2020; Rana \& Sharma, 2020). All the aforementioned studies have explored similar perspectives, in which the effect of FDI on the $\mathrm{CO} 2$ emissions has been examined and not the other way round, and they mostly reported the positive effect, with some few exceptions in the case of Do and Dinh (2020), who found the results showed a negative effect after some period of time, and Mahmood et al. (2020), who did not found any significant relationship between the two.

It is critical to study how FDI inflow is affected by the amount of $\mathrm{CO} 2$ remitted since investors consider many things, including environmental factors, before committing their resources (Yüksel et al., 2020). Apart from these authors (Yüksel et al., 2020), who studied the negative effect of $\mathrm{CO} 2$ remittance on FDI inflows, no other study has made a similar attempt. However, their bivariate study ignored other important variables, of which their inclusion alongside $\mathrm{CO} 2$ would have improved the credibility of their conclusions.

\section{Empirical Literature Review}

The pool of literature that focuses on the economic factors identified market size, labour cost, trade openness, economic stability, absorptive capacity, economic growth, wages, etc. as significant determinants of FDI inflows (Schneider \& Frey, 1985; Torissi, 1985; Tsai, 1994; Hailu 2010; Leitao \&.Faustino, 2010; Mohamed \& Sidiropoulos, 2010; Schneier \& Matei 2010; Ting \& Tang, 2010; Bhavan et al., 2011; Buchanan \& Jadhav, 2012; Quan \& Rishi, 2012; Agrawal, 2015 )

Other studies have observed that institutional factors, like rule of law, control of corruption, tax and fiscal policies, regulatory quality, government effectiveness, political stability and infrastructure, enhanced FDI inflows. (King \& Levine, 1993; Gani, 2007; Ali et al., 2010; Jadhav, 2012; Agrawal, 2015). 
The role of energy consumption and its attending environmental consequences are missing from the above literature. Although numerous FDI-energy or FDI and environment literature are recently available (Essandoh et al., 2019; Yilanci, 2019; Akram, 2020; Do \& Dinh, 2020; Jiang et al., 2020; Mahmood et al., 2020; Mukhtarov et al., 2020; Nguyen et al., 2020; Rana \& Sharma, 2020; Wang et al., 2020; Yüksel., et al. 2020), they are mainly on the role of FDI on energyrelated variables, but not the other way round, except for a recent study by Yüksel, et al. (2020), who uses a bivariate model to prove the negative effect of $\mathrm{CO} 2$ on FDI.

Essandoh et al. (2019) studied both developed and developing economies in terms of the environmental effect of trade and FDI and suggested that both are critical forces in determining $\mathrm{CO} 2$ emissions. They also established a positive effect of FDI on $\mathrm{CO} 2$ in developing countries, based on which it is held that through FDI, the emission-intensive method of production would be shifted to developing countries. Mahmood et al. (2020) combined FDI, export, import and $\mathrm{CO} 2$ in his study on developing countries. Noticing the negative effect of export on $\mathrm{CO} 2$, the import and openness in contrast produced positive results. However, they failed to find any significant linkage between FDI and $\mathrm{CO} 2$. Another study was conducted on emerging economies by Nguyen et al. (2020) and was based on the economic integration-FDI nexus. The empirical findings revealed that FDI inflow significantly increase $\mathrm{CO} 2$ emissions in both the short and the long run, while openness produces a negative effect on $\mathrm{CO} 2$ in the long run and a positive effect in the short run.
Using Modified Wald, Rana and Sharma (2020) checked the causality of FDI, GDP and environment alongside the openness and technological gap over the period of 19802014. They were able to traced the causality from FDI to trade and $\mathrm{CO} 2$, which signifies that FDI is the source of environmental degradation via energy consumption and its resulting $\mathrm{CO} 2$ remittance in India. Another time series study was conducted by Do and Dinh (2020) using similar combination of variables used by Rana and Sharma (2020) in Vietnam. Their result from vector error correction model reveals that FDI have a positive effect on $\mathrm{CO} 2$, while all other variables exhibit a contrary result. Mukhtarov et al. (2020) observed the FDI-CO2 nexus in Azerbaijan and suggested that FDI produce a positive impact on $\mathrm{CO} 2$ up to 2006, and subsequently, the effect turned to be negative.

An attempt similar to this paper was made by Yüksel et al. (2020) who conducted a comparative study on the negative effect of $\mathrm{CO} 2$ on FDI between the panel of G7 and E7 countries. They found that $\mathrm{CO} 2$ reported a negative effect for both groups. However, the negativity of the effect was found to be stronger in G7 than in E7, and they reported no causality between FDI and $\mathrm{CO} 2$ in both groups. One of the conclusions of the study is the need for these groups of countries to minimise carbon emissions.

\section{Model, Data and Methodology}

This study used the panel data of BRICS countries over the period of 1995-2018 as warranted by the availability of data. The dependent variable in this study is FDI inflow and independent variables are chosen based on their relevance to this study and the reviewed literature. Thus, the following is how they are placed in the model:

$$
l F D I_{i t}=\beta_{0}+\beta_{1} l G D P_{i t}+\beta_{2} l C O 2_{i t}+\beta_{3} l E X C_{i t}+\beta_{4} l c p i_{i t}+\varepsilon_{i t}
$$


Where 1FDI is the log of Foreign Direct Investment inflows, GDP is the log of Gross Domestic Product, which stands for market size, IEXC is the log of exchange rate, $1 \mathrm{CO} 2$ is the $\log$ of $\mathrm{CO} 2$ i.e. the carbon emissions and 1CPI is the $\log$ of policy variable, which stands for inflation rate. All the variables are in US dollars for country $\mathrm{i}$ at time $\mathrm{t}$ and are sourced from World Bank's world development indicators' website (WDI).

We applied a panel data technique and this is necessary because of its advantages over its cross-section and time series counterparts. It helps to exploit all the information that is not detectable in ordinary cross-sectional or pure time series method (Baltagi \& Kao, 2000). It is also capable of abating the risk of obtaining biased results by providing more observations and thereby increasing the degrees of freedom. Accordingly, other panel techniques were used to examine the internal structure of individual series, as well as the dynamic relationship between all the variables in the model prior to the estimation, e.g. a cross-section dependency tests, panel unit-root tests and corresponding panel co-integration tests are applied prior to the estimation.

The study preliminarily examines the variables by observing their univariate distributions as reported in Table 1, and it is found that there are great disparities among them in terms of means and standard deviations. We also found that the null hypothesis of normality has been rejected across the variables. This prompts the use of log transformation across the series. The correlation examination among the variables from Table 2 reveals that all, except the log of exchange rate, are probably positively correlated with FDI.

Table 1: Summary statistics for the whole dataset

\begin{tabular}{lccccc}
\hline \multicolumn{1}{c}{ Statistics } & FDI & GDP & EXC & CO2 & CPI \\
\hline Mean & 2.279672 & 9885.570 & 19.57213 & 2138942. & 0.429207 \\
Median & 2.123121 & 8573.664 & 8.277659 & 1355662. & 0.384549 \\
Maximum & 5.978862 & 26544.00 & 68.38947 & 10291927 & 0.937872 \\
Minimum & 0.229311 & 1485.029 & 0.917667 & 258347.5 & 0.147519 \\
Std. Dev. & 1.372889 & 6244.947 & 19.85190 & 2686782. & 0.195168 \\
Skewness & 0.372731 & 0.891012 & 1.016521 & 2.031331 & 0.694467 \\
Kurtosis & 2.111506 & 3.406282 & 2.701825 & 6.084135 & 2.558220 \\
Jarque-Bera & 6.725675 & 16.70339 & 21.11085 & 130.0855 & 10.62154 \\
Probability & $0.034 * *$ & $0.000^{* * *}$ & $0.00^{* * *}$ & $0.00^{* * * *}$ & $0.00^{* * *}$ \\
\hline
\end{tabular}

ÔH0: the series is normally distributed, $* * *, * *$ and $*$ indicates significance of Jarque-Bera statistic at the level of $1 \%, 5 \%$ and $10 \%$ respectively

Table 2: Correlation matrix

\begin{tabular}{lccccc}
\hline & IFDI & IGDP & ICO2 & IEXC & ICPI \\
\hline IFDI & 1.00 & & & & \\
IGDP & 0.15 & 1.00 & & & \\
ICO2 & 0.26 & -0.13 & 1.00 & & \\
IEXC & -0.23 & -0.25 & 0.37 & 1.00 & \\
ICPI & 0.21 & 0.72 & -0.25 & -0.60 & 1.00 \\
\hline
\end{tabular}

Source: Authors' computation 


\section{Cross-sectional Dependence}

In traditional panel data analysis, it is assumed that the cross-sectional units are independent. However, this assumption is often violated in a recently used panel-time series set-up. This is the result of the shocks that may have emanated from international economics' inter-relations, which affect all countries in a different manner, although it has a common source (Ebierhart \& Teal, 2001; Baltagi et al., 2012). This causes inter-dependence among the cross-sectional units in the datasets. Therefore, it is important

that the variables be subjected to the crosssectional dependence test, Otherwise, the result may be hampered by bias and size distortion (Breusch \& Pagan, 1980)

\section{Breusch Pagan Lagrange Multiplier Test}

This is an appropriate test only when dealing with the panel datasets involving small number of cross-sections and sufficiently large number of time dimension (Breusch \& Pagan, 1980; Baltagi et al., 2012). It involves the use of the following test statistic

$$
\mathrm{LM}=\sum_{i=1}^{N-1} \sum_{K=i+1}^{N}\left(T \hat{\rho}_{i k}^{2}-1\right) \rightarrow \chi^{2} \frac{N(N-1)}{2}
$$

The term $\hat{\rho}_{i j}^{2}$ is the resulting pairwise correlation estimate from the given OLS residual, the LM statistic follows asymptotically chi-square distribution for a given null of no cross-sectional correlation, in which the degree of freedom is given as $\chi^{2} \frac{N(N-1)}{2}$. It tests the null as HO: $\operatorname{cov}\left(e_{j t} e_{i t}\right)=0$ for $\mathrm{i} \neq \mathrm{j}$.

The LM test has its downside as it is not applicable to datasets involving substantial number of cross-sectional units.

\section{Pesaran Scaled LM Test}

To contain the problem associated with the LM test, Pesaran (2004) proposed the scaled version of LM in the form of the below equation (2):

$$
C D L M=\left(\frac{1}{N(N-1)}\right)^{\frac{1}{2}} \sum_{i=1}^{N-1} \sum_{K=i+1}^{N}\left(T \hat{\rho}_{i k}^{2}-1\right) \rightarrow N(0,1)
$$

This equation is applied even when both the time and individual dimensions of the series are substantially large. This equation also has its own deficiency of size distortion when the time dimension is low.

\section{Pesaran CD Test}

Pesaran (2004) claimed to have addressed the drawback of both the LM and scaled LM by using the CD equation below:

$$
C D=\sqrt{\frac{2 T}{N(N-1)}}\left(\sum_{i=1}^{N-1} \sum_{k=i+1}^{N} \hat{\rho}_{i k}\right) \rightarrow N(0,1)
$$

The test is an improvement to the scaled test to allow for the application in a situation where the time dimension of the series is small. This statistic is based on the ith and N-1 pairwise correlation coefficient that is calculated for a given ADF model. It has many advantages as it is applied to both balanced and unbalanced data, and it is robust against dynamic heterogeneity in the model. It is also applicable to non-stationary models, as well as models with the structural break(s).

\section{Baltagi, Tend and Kao Biased Corrected Scaled LM (LMBC)}

The LMBC of scaled LM by Baltagi et al. (2012) is said to have the asymptotic bias term, which arises as a result of the accidental 


$$
L M B C=\left(\frac{1}{N(N-1)}\right)^{\frac{1}{2}} \sum_{i=1}^{N-1} \sum_{K=i+1}^{N}\left(T \hat{\rho}_{i k}^{2}-1\right)-\frac{N}{2(T-1)} \rightarrow N(0,1)
$$

parameter from a small $\mathrm{T}$ property that resulted in the imprecise estimate of the within residual. However, the equation has its bad side as it is based on homogeneous parameter.

\section{Pesaran and Yamagata Test for the} Homogeneity of the Slope

The Pesaran and Yamagata (2008) test is based on the null of slope homogeneity against the alternative of the heterogeneous slope. Unlike Swamy (1970), this test is robust against autocorrelation across sections.

The test equation or standardized version of dispersion is given by:

$\tilde{\Delta}_{i j}=\sqrt{N}\left(\frac{N^{-1} \tilde{S}-K}{\sqrt{2 K}}\right.$ in the case of the large sample and

$$
\operatorname{adj} \tilde{\Delta}_{i j}=\sqrt{N}\left(\frac{N^{-1} \tilde{S}-E\left(\widetilde{Z_{I \tau}}\right)}{\operatorname{var} \sqrt{\left(\widetilde{Z_{I \tau}}\right)}}\right.
$$

in the case of the small sample.

\section{Stationary Test}

This paper adopted the two versions of the unit roots test, i.e. the first generation test by Maddala and $\mathrm{Wu}$ (1999), and the second generation (CIPS) test.

\section{Maddala and Wu-Fisher Test}

When applied to cross-sectional independence datasets, the Maddala and Wu (1999) version of Fisher test is based on the ADF equation as the following:

$$
\Delta y_{i t}=\alpha_{i}+\rho_{i} y_{i t-1}+\sum_{j=0}^{k} \delta_{i j} y_{i t-1}+\varepsilon_{i t}
$$

It combines the p-values from different unit root test, and the test has the asymptotic distribution of the null hypothesis as

$$
\mathrm{ADFmw}=-2 \sum_{j=0}^{k} \log \left(\pi_{j}\right) \rightarrow x^{2}{ }_{2} N
$$

Where is the unit roots from different individual tests.

\section{Pesaran (2007) CIPS Test}

The Pesaran (2007) CIPS tset is the cross-sectional augmented version of the IPS test, and augmented version of $\mathrm{ADF}$ equation in the form of equation (10):

$$
\Delta y_{i t}=\alpha_{i}+\rho_{i} y_{i t-1}+\beta_{i} \bar{y}_{t-1}+\sum_{j=0}^{k} \gamma_{i j} \Delta \bar{y}_{i t-1}+\sum_{j=0}^{k} \delta_{i j} y_{i t-1}+\varepsilon_{i t}
$$

The test uses the CIPS equation below (11):

$$
C I P S=\frac{1}{N} \sum_{I=1}^{N} t_{i}(N, T)
$$

The term is the ADF equation across ith countries for the t-ratio parameter from equation (11).

\section{Bootstrapped Westerlund Error-correction Based Co-integration Test}

Westerlund (2007) proposed a cross-sectiondependent robust error-correction test. The test is based on the bootstrap version of four test equation grouped into two to test for the null hypothesis of no error-correction term in the equation of the form of (12). 


$$
\Delta Y_{i t}=\delta_{i}^{\prime} d_{t}+\alpha_{i} Y_{i t-1}+\lambda_{i}^{\prime} X_{i t-1}+\sum_{j=1}^{\rho i} \alpha_{i j} \Delta y_{i t-j}+\sum_{j=0}^{\rho i} \gamma_{i j} \Delta X_{i t-j}+\mu_{i t}
$$

Based on the equation (12) above, the group equations (13) are used to test against the alternative hypothesis of co-integration in at least one of the ith cross-sectional units.

$$
G_{\tau}=\frac{1}{N} \sum_{i=1}^{N} \frac{\widehat{\alpha}_{i}}{S E\left(\widehat{\alpha}_{i}\right)} \quad G_{\alpha}=\frac{1}{N} \sum_{i=1}^{N} \frac{T \widehat{\alpha}_{i}}{\widehat{\alpha}_{i}(1)}
$$

While the panel equations (14) are used to test the null of no co-integration for the whole panel against the alternative of co-integration in the whole.

$$
P_{\tau}=\frac{\widehat{\alpha}}{S E(\widehat{\alpha})} \text { dan } P_{\alpha}=T \hat{\alpha}
$$

These test equations are more powerful because of the small sample properties, as well as the lesser size distortions, in addition to its ability to account for cross-sectional dependency.

\section{Continuously Updated Panel Fully Modified Estimator (CUP-FM)}

Bai et al. (2006) came up with the estimator that account for cross-sectional dependency. It is evolved through repeated application of rule and procedure to estimate the long-run covariance matrix, the parameter and estimate of factor loading. This estimator has a better small sample quality.

$$
\begin{aligned}
& \hat{\beta}_{C U P}=\left[\sum_{i=1}^{n}\left(\sum_{t=1}^{T} \hat{y}_{i t}^{+}\left(\hat{\beta}_{C U P}\right)\left(x_{i t}-\bar{x}_{i}\right)^{\prime}-T\left(\hat{\lambda}^{\prime}\left(\hat{\beta}_{C U P}\right) \hat{\Delta}_{F \varepsilon i}^{+}\left(\hat{\beta}_{C U P}\right)+\Delta_{u \varepsilon i}^{+}\left(\hat{\beta}_{C U P}\right)\right)\right)\right] \\
& *\left[\sum_{i=1}^{n} \sum_{t=1}^{T}\left(x_{i t}-\bar{x}_{i}\right)\left(x_{i t}-\bar{x}_{i}\right)^{\prime}\right]^{-1}
\end{aligned}
$$

\section{Dumitrescu and Hurlin Causality Test}

The Dumitrescu and Hurlin (2012) methodology tests the null hypothesis for homogeneous noncausality, which account for heterogeneity and possible dependency across individual units (further step is taken to tackle the cross-sectional dependency through block-bootstrap procedure).

$$
\begin{aligned}
& y_{i t}=\propto_{i}+\sum_{k=1}^{K} \gamma_{i}^{(k)} y_{i t-k}+\sum_{k=1}^{K} \beta_{i}^{(k)} x_{i t-k}+\varepsilon_{i t} \\
& x_{i t}=\emptyset_{i}+\sum_{k=1}^{K} \emptyset_{i}^{(k)} x_{i t-k}+\sum_{k=1}^{K} \emptyset_{i}^{(k)} y_{i t-k}+\varepsilon_{i t}
\end{aligned}
$$

The methodology applies to the above the parameter of any individual cross-section system, and it takes into account the possibility differs from the rest, and one goes ahead with that $B_{i} \neq B_{j}$. This is important because there may the homogeneous assumption (Dumitrescu \& be a risk of making the wrong interpretation if Hurlin, 2012).

$\mathrm{H} 0$ : no causality from $\mathrm{x}$ to $\mathrm{y}$ in the whole cross-section (i.e. Homogeneous causality)

Hi: case $1 \beta_{i}<0, i \&=1,2, \ldots \ldots N_{1}$ : there is causality in some parts of cross-sections;

Hi: case $2 \beta_{i}=0, i \&=N_{1}+2 \ldots N$ : there is no causality in some parts of cross-sections.

$$
\begin{aligned}
& W=\frac{1}{N} \sum_{i=1}^{N} W_{i}, T \\
& Z=\sqrt{\frac{N}{2 K}}(W-K)
\end{aligned}
$$




\section{Empirical Results}

This section reported the results from all the techniques discussed in the preceding section. The pre-estimation examinations begin by checking the possibility of cross-section correlation for each of the variables and the result is presented in Table 3 .

All the test statistics consistently rejected the null of cross-sectional dependency, except the CD-test in the case of the log of FDI. We also test for the heterogeneity of the slope using Pesaran and Yamagata (2008). The delta equation accepted the null hypothesis, while the adjusted delta equation rejected the null hypothesis of homogenous slopes as reported in Table 4.

Based on the preceding tests, we resorted to use both the first and the second-generation unit roots techniques, i.e. the one accounting for cross-section correlations and that which cannot.

Table 5 reported the panel unit root tests, the Maddala and $\mathrm{Wu}$, and CIPS versions. From Panel A of Table 5, the Fisher equation reveals that all the variables are I(1), i.e. if the crosssection correlation is been ignored, all the variables are integrated at first difference, and when we consider the cross-sectional correlation as in Panel B of Table 5, the log of $\mathrm{CO} 2$ and the

Table 3: Cross-sectional dependency test

\begin{tabular}{lcccc}
\hline & Breusch-Pagan LM & Pesaran Scaled LM & Bias-corrected Scaled LM & Pesaran CD \\
\hline 1FDI & $20.46(0.03)$ & $2.24(0.02)$ & $2.23(0.03)$ & $1.21(0.23)$ \\
1GDP & $233.6(0.00)$ & $49.9(0.00)$ & $49.8(0.00)$ & $15.28(0.00)$ \\
1CO2 & $179.3(0.00)$ & $37.85(0.00)$ & $37.85(0.00)$ & $13.24(0.00)$ \\
1EXC & $150(0.00)$ & $31.3(0.00)$ & $31.19(0.00)$ & $4.60(0.000)$ \\
1CPI & $143.9(0.00)$ & $29.93(0.00)$ & $29.82(0.00)$ & $11.87(0.00)$ \\
\hline
\end{tabular}

HO: no cross-sectional correlation; p-values in bracket; ***,** and * indicates significance at the level of $1 \%$, $5 \%$ and $10 \%$, correspondingly

Table 4: Slope heterogeneity test

H0: slope coefficients are homogenous

\begin{tabular}{ccc}
\hline Swarmy & Statistics & p-value \\
\hline$\widetilde{\Delta}_{i j}$ & -1.37 & 0.17 \\
$\operatorname{adj} \tilde{\Delta}_{i j}$ & -2.03 & $0.04^{* *}$ \\
\hline
\end{tabular}

Source: Authors computation;***,** and * indicates significance at the level of $1 \%, 5 \%$ and $10 \%$ correspondingly

Table 5: Panel unit root test

Panel A - Maddala and Wu (1990)

\begin{tabular}{|c|c|c|c|c|c|c|c|c|c|c|}
\hline & \multirow[b]{2}{*}{ IFDI } & \multicolumn{3}{|c|}{ Constant } & \multirow[b]{2}{*}{ ICPI } & \multirow{2}{*}{$\begin{array}{c}\text { Constant } \\
\text { IFDI }\end{array}$} & \multirow{2}{*}{$\begin{array}{l}\text { with } \\
\text { IGDP }\end{array}$} & \multirow{2}{*}{$\begin{array}{l}\text { trend } \\
\text { ICO2 }\end{array}$} & \multirow[b]{2}{*}{ IEXC } & \multirow[b]{2}{*}{ ICPI } \\
\hline & & IGDP & ICO2 & IEXC & & & & & & \\
\hline & 13.99 & 3.02 & 3.84 & 8.14 & 5.86 & 7.98 & 3.41 & 12.84 & 9.81 & 5.73 \\
\hline $\mathrm{k}$ & 2 & 1 & 1 & 1 & 2 & 2 & 1 & 1 & 1 & 2 \\
\hline \multirow[t]{2}{*}{2} & $\Delta$ LFDI & $\Delta$ LGDP & $\triangle \mathrm{LCO2}$ & $\triangle \mathrm{IEXC}$ & $\triangle \mathrm{ICPI}$ & & & & & \\
\hline & $61.33^{\mathrm{a}}$ & $14.21^{\mathrm{a}}$ & $39.87^{\mathrm{a}}$ & $30.34^{\mathrm{a}}$ & $38.87^{\mathrm{a}}$ & Nil & Nil & Nil & Nil & Nil \\
\hline $\mathrm{k}$ & 1 & 0 & 1 & 1 & 1 & & & & & \\
\hline
\end{tabular}

H0: slope coefficients are homogenous; $* * *(a), * *(b)$ and $*(c)$ indicates significance at the level of $1 \%, 5 \%$ and $10 \%$ correspondingly 
Panel B - Pesaran (2007) CIPS Test-Level

\begin{tabular}{ccccccccccc}
\hline & & & Constant & Level & & Constant & with & trend & & \\
\hline & IFDI & IGDP & ICO2 & IEXC & ICPI & IFDI & IGDP & ICO2 & IEXC & ICPI \\
& 1.15 & 1.10 & $-3.33^{* * *}$ & 1.33 & $-2.45^{* * *}$ & 0.92 & 0.06 & -0.75 & -0.43 & -0.66 \\
$\mathrm{k}$ & 1 & 1 & 1 & 1 & 2 & 1 & 1 & 1 & 1 & 1 \\
\hline & $\Delta \mathbf{L F D I}$ & $\Delta \mathbf{I G D P}$ & $\Delta \mathbf{L C O 2}$ & $\Delta \mathbf{I E X C}$ & $\Delta \mathbf{I C P I}$ & & & & & \\
& $-3.36^{\mathrm{a}}$ & $-1.97^{\mathrm{b}}$ & $\mathrm{Nil}$ & $-3.23^{\mathrm{a}}$ & $\mathrm{Nil}$ & $\mathrm{Nil}$ & $\mathrm{N}$ Nil & Nil & Nil & Nil \\
$\mathrm{k}$ & 1 & 1 & & 1 & & & & & & \\
\hline
\end{tabular}

Source: Authors computation; $* * *(a), * *(b)$ and $*(c)$ indicates significance at the level of $1 \%, 5 \%$ and $10 \%$ correspondingly, and $\mathrm{k}$ is the lag order

$\log$ of CPI are stationary at level and the log of FDI, log of GDP and log of EXC are stationary at first difference.

The bootstrapped version of the Westerlund panel co-integration result is presented in Table 6 , and it is found that based on the bootstrapped probabilities and accompanying Ga test statistics, and the null of absence of co-integration will be overruled.

The relationship between the log of FDI and all the remaining explanatory variable, especially the $\log$ of $\mathrm{CO} 2$ (the environmental implication of energy consumption), is examined in Table 7. The result is based on CUP-FM as reported in Table 7, the determinants of FDI observed are the log of GDP, $\log$ of EXC and $\log$ of CO2.

The positive co-efficient is reported by the $\log$ of GDP and this is in line with the results by Kumar (1994), Asiedu (2002), Ranjan and Agrawal (2011) Jadhav (2012) and Kim et al. (2013). This is more so, as the size of the economy is reflected in its GDP (see also, Jadhav, 2012) and being the home of about $23.3 \%$ of the global GDP and the fact that

Table 6: Westerlund (2007) panel co-integration test

\begin{tabular}{|c|c|c|c|c|c|c|c|c|c|}
\hline & & Constan & & & & Constant & with & trend & \\
\hline Stats & Value & Z-val & p-val & boostrap-p & Stat & Value & Z-val & P-val & Boostrap-p \\
\hline Gt & -10.7 & -19.2 & $0.00 * * *$ & $0.00 * * *$ & Gt & -3.04 & -1.89 & $0.03 * *$ & $0.05 * *$ \\
\hline $\mathrm{G} \alpha$ & -0.8 & 3.6 & 1.00 & 0.91 & $\mathrm{G} \alpha$ & -8.5 & 1.14 & 0.87 & 0.47 \\
\hline $\mathrm{Pt}$ & -4.3 & 0.4 & 0.67 & 0.17 & $\mathrm{Pt}$ & -6.1 & -1.58 & $0.05 * *$ & 0.14 \\
\hline $\mathrm{P} \alpha$ & -0.4 & 2.6 & 0.99 & 0.94 & $\mathrm{P} \alpha$ & -8.99 & 10.02 & 0.49 & 0.24 \\
\hline
\end{tabular}

H0: no co-integration $* * *, * *$ and $*$ indicates significance at the level of $1 \%, 5 \%$, and $10 \%$, respectively

Table 7: Long-run coefficients CUP-FM

\begin{tabular}{|c|c|c|}
\hline \multirow[t]{2}{*}{ Variable } & \multicolumn{2}{|c|}{ CUP-FM } \\
\hline & Coefficient & t-statistic \\
\hline 1GDP & 1.54 & $2.06^{* *}$ \\
\hline $1 \mathrm{CO} 2$ & 1.14 & $5.33 * * *$ \\
\hline 1EXC & 0.44 & $1.87^{*}$ \\
\hline 1CPI & -0.15 & $3.99 * *$ \\
\hline
\end{tabular}

Source: Author's computations. Note: ***,** and $*$ indicates significance at the level of $1 \%, 5 \%$ and $10 \%$, correspondingly 
BRICS have been among the world's most stable economies in terms of GDP growth, it stands to reason that BRICS would be attractive to any investor,particularly those driven by market seeking. The negative sign is reported by the log of CPI and this agrees with the findings by Ranjan and Agrawal (2011). However, it is not on the same page with Jadhav (2012). The negative CPI could be the result of the higher cost of production and in turn low profits, which discourage the FDI inflows (see, Kim et al., 2013; Bahri et. al, 2018). This may indicate that more studies are needed on the credibility of the anti-inflationary measures taken by the member countries. The implications of environmental quality on FDI are traced from the coefficient of CO2. Contrary to Yüksel et al. (2020), we reported a positive co-efficient, and this is true looking at the type of technologies brought by FDI, which are mostly hyper-emissions in nature (see also, Essandoh et al., 2019), and it may create a perception that since those countries are still in need of foreign investments inflows, the regulatory bodies responsible for ensuring the compliance to the requirements of the environmental protection rules may tend to be lenient to the violators. Another justification of this finding is by Yüksel et al. (2020), where they attributed the negative result in their study to the G7 countries.

Lastly, we used the Dumitrescu and Hurlin (2012) causality procedure to check the robustness of the above estimator and reported the result in Table 8. This technique has the blocked-bootstrapped procedure that account for correlations across individuals. In addition to its ability to contain parameter heterogeneity, it also applied irrespective of the length of crosssections or time dimensions.

The result as reported in Table 8 suggested no causality between the log of FDI and the $\log$ of $\mathrm{CO} 2$, and this is also the case in Yüksel et al. (2020). However, the application of this procedure and the nature of the hypothesis allow for the possibility of the causality to still hold at the individual country level. Therefore, the rejection of the null hypothesis does not rule out the possibilities that FDI causes $\mathrm{CO} 2$ and vice versa, in some of the countries. The rest of the finding from same table also reveal the bidirectional causality between the log of GDP and $\log$ of FDI, and the same thing is also reported in the case of inflation, while a one 0 way causality is found from the log of ECX to log of $\mathrm{CO} 2$.

\section{Conclusion and Policy Recommendations}

Using the panel data for BRICS countries from 1995 to 2018, we have empirically examined $\mathrm{CO} 2$ alongside the other traditional determinants of FDI. In this process, we cross-examined the datasets in term of the possible correlations across sections, slope homogeneity and unit roots, as well as the co-integrations, and all are preceded by the examination of the individual statistical distributions of each variable, and the correlation among them is evaluated as well. All the results are reported in Tables 1 to 6 .

Appropriate techniques were adopted for the estimation to ensure robust analysis and

Table 8: Dumitrescu and Hurlin (2012) bootstrapped panel causality

\begin{tabular}{|c|c|c|c|c|c|c|c|c|c|c|}
\hline \multirow[t]{2}{*}{$\begin{array}{l}\text { Dependent } \\
\text { Variable }\end{array}$} & \multirow{2}{*}{$\begin{array}{c}\text { Statistics } \\
\text { Wald }\end{array}$} & \multicolumn{3}{|c|}{$\begin{array}{l}\text { Bootstrapped crit- } \\
\text { val }\end{array}$} & \multirow{2}{*}{ Variables } & \multirow{2}{*}{$\begin{array}{c}\text { Statistics } \\
\text { Wald }\end{array}$} & \multicolumn{4}{|c|}{ Bootstrapped crit-val } \\
\hline & & $99 \%$ & $95 \%$ & $90 \%$ & & & $99 \%$ & $95 \%$ & $90 \%$ & \\
\hline FDI & $68.14 * * *$ & 36.6 & 15.6 & 10.3 & GDP & $3.41 * *$ & 3.94 & 2.38 & 1.75 & $\leftrightarrow$ \\
\hline FDI & 0.69 & 5.34 & 4.36 & 3.24 & $\mathrm{CO} 2$ & 0.91 & 3.97 & 2.90 & 2.14 & \\
\hline FDI & 1.23 & 7.46 & 3.22 & 2.27 & EXC & $2.86^{*}$ & 4.23 & 3.09 & 2.37 & $\leftarrow$ \\
\hline FDI & $35.9 * * *$ & 26.9 & 10.7 & 7.51 & CPI & $89.8^{* * *}$ & 11.1 & 6.82 & 4.46 & $\leftrightarrow$ \\
\hline
\end{tabular}

HO: GDP, CO2, EXC and CPI do not cause FDI HO: FDI does not Granger cause GDP, CO2, EXC and CPI $* * *, * *$ and $*$ indicates significance at the level of $1 \%, 5 \%$ and $10 \%$, correspondingly 
policy prescriptions. The results of the CUPFM estimator revealed that IGDP, IEXC, and $1 \mathrm{CO} 2$ are positively related with FDI, and a negative relationship is reported between ICPI and lFDI. Therefore, we can deduce that market size, carbon emissions, and lower exchange rate attract FDI, while higher exchange rate and higher prices (inflation) discourage FDI inflows to BRICS. In addition, one can also deduce that apart from the traditional variables observed in this study (i.e. GDP, EXC and CPI), carbon emissions (CO2) is also an important determinant of FDI in BRICS countries during the study period. The bidirectional causality is reported between FDI and GDP, CPI and FDI, and a onedirectional causality is found between FDI and EXC. However, no such a causal relation is reported between FDI and $\mathrm{CO} 2$, and this could be the case that the causality still holds in some but not all the countries. This is true as this strong causality between GDP and FDI should always be the case in developing countries, and so developing countries may likely be concerned more about the economic growth rather than environmental issues, and consequently, they are sceptical about the imposition of an excessive amount of carbon tax out of fear of losing foreign investments. Foreign investors would also take into account the cost implication of the amount of carbon tax charged in any prospective destinations.

In this study, we recommend that designing of any FDI-incentive policy should take into account environmental issues, as the tradeoff would always be there concerning the amount of the carbon tax and such policies designed to attract FDI. More should be done in the generation of environmentally sustainable energy. Policymakers should ensure that decisions taken will not yield sub-optimal results as the sustainability of the environment should always be given priority. Although there seems to be a stability in the BRICS economies, more should be done to ensure that the credibility of anti-inflationary measures are improved; the stability of exchange rates should also be ensured by policymakers. It is also of great importance for policymakers to be committed to safeguarding job security, to maintain and even improve the current trend of GDP, and this will in turn enhance the rate of FDI inflows and subsequent job creation.

The inclusion of carbon tax into our model and the determination of its optimum amount would have added value to the findings. The asymmetry effect of exchange rate should have also been considered to find out how FDI would respond to the rise and the fall in the value of domestic currencies. However, these would require the use of non-linear modeling, which is not considered in this study and it is recommended that future research explore this.

\section{Acknowledgements}

This research is the part of the ongoing thesis work at the Department of Econometrics SRM IST, Chennai, India -603203. It is part of the requirement for the completion of $\mathrm{PhD}$ in Econometrics.

\section{References}

A, Levin. C, F, Lin. C, Chu. (2002). Unit Root Tests in panel data: Asymptotic and finitesample properties. Journal of Econometrics, 108, 1-24.

Agarwal, J. P. (1980). Determinants of foreign direct investment: A survey. Weltwirtschaftliches Archiv, 116, 739-77.

Akram, R., Majeed, M. T., Fareed, Z., Khalid, F., \& Ye, C. (2020). Asymmetric effects of energy efficiency and renewable energy on carbon emissions of BRICS economies: Evidence from nonlinear panel autoregressive distributed lag model. Environmental Science and Pollution Research, 1-15.

Ali, F., Fiess, N., \& MacDonald, R. (2010). Do institutions matter for foreign direct investment?

Azam, M. (2010). An empirical analysis of the impacts of exports and foreign direct investment on economic growth in 
South Asia. Interdisciplinary Journal of Contemporary Research in Business, 2(7).

Bahri, E. N. A., Nor, M., Shaari, A. H., Nor, M., \& Haji, N. H. (2018). The role of financial development on foreign direct investment in Asean-5 countries: Panel cointegration with cross-sectional dependency analysis. Asian Academy of Management Journal of Accounting \& Finance, 14(1).

Bai, J., \& Kao, C. (2005). On the estimation and inference of a panel cointegration model with cross-sectional dependence. Syracuse University Center for Policy Research Working Paper, (75).

Bai, J., \& Kao, C. (2006). On the estimation and inference of a panel cointegration model with cross-sectional dependence. Contributions to economic analysis, 274, 3-30.

Baltagi, B. H., Feng, Q., \& Kao, C. (2012). A Lagrange Multiplier Test for cross-sectional dependence in a fixed effects panel data model. Journal of Econometrics, 170(1), 164-177.

Baltagi, B. H., \& Kao, C. (2000). Nonstationary panels, cointegration in panels and dynamic panels: A survey. Center.

Bhavan, T., Xu, Changsheng., \& Zhong, C. (2011). Determinants and growth effect of FDI in South Asian economies: Evidence from a panel data analysis. International Business Research, 4(1).

Blomstrom, M. (1989). Foreign investment and spillovers: A study of technology transfer to Mexico. London: Routledge.

Breusch, T. S., \& Pagan, A. R. (1980). The Lagrange multiplier test and its applications to model specification in econometrics. The Review of Economic Studies, 47(1), 239253.

Buchanan, B. G., Le, Q. V., \& Rishi, M. (2012). Foreign direct investment and institutional quality: Some empirical evidence. International Review of Financial Analysis, 21, 81-89.
Cheng, H., F., Gutierrez, M., Mahajan, A., Shachmurove, Y., \& Shahrokhi, M. (2007). A future global economy to be built by BRICs. Global Finance Journal, 18, 143-156, doi:10.1016/j.gfj.2006.04.003,http://dx.doi. org/10.1016/10.1016/j.gfj.2006.04.003

Do, T., \& Dinh, H. (2020). Short-and longterm effects of GDP, energy consumption, FDI, and trade openness on $\mathrm{CO} 2$ emissions. Accounting, 6(3), 365-372.

Dumitrescu, E. I., \& Hurlin, C. (2012). Testing for Granger non-causality in heterogeneous panels. Economic Modelling, 29(4), 14501460.

Dunning, J. H. (1981). International production and multinational enterprise, Allen \& Unwin, 35, 149-66.

Dunning, J. H. (1993). The theory of transnational corporations. London: Routledge. 16-18.

Durán, J. E. (1999). Los determinantes de la ied en los países de américa latina y el caribe: su impacto sobre el comercio y la integración regional, ECLAC, Mimeo. for Policy Research, Working Paper, No. 16, Syracuse University, Syracuse, NY.

Eberhardt, M., \& Presbitero, A. F. (2015). Public debt and growth: Heterogeneity and non-linearity. Journal of International Economics, 97(1), 45-58.

Essandoh, O. K., Islam, M., \& Kakinaka, M. (2020). Linking international trade and foreign direct investment to $\mathrm{CO} 2$ emissions: Any differences between developed and developing countries? Science of The Total Environment, 712, 136437.

Helpman, E. (1984). A simple theory of international trade with multinational corporations, Journal of Political Economy, 92(3), 451-471.

Hymer, S. H.(1960) The internationaloperations of national firms: A study of direct investment (Ph.D thesis). Cambridge,MA: MIT press. 
IEA. (2013). Redrawing the energy-climate map: World energy outlook special report. OECD/IEA.

Jadhav, P. (2012). Determinants of foreign direct investment in BRICS economies: Analysis of economic, institutional and political factor. Procedia-Social and Behavioral Sciences, 37, 5-14.

Journal of Econometrics, 142(1), 50-93.

Ju, J., \& Wei, S. -J. (2007). Domestic institutions and the bypass effect of financial globalization.

Kim, D. H., Lin, S. C., \& Suen, Y. B. (2013). Investment, trade openness and foreign direct investment: Social capability matters. International Review of Economics \& Finance, 26, 56-69.

Kishor, N., \& Singh, R. P. (2015). Determinants of FDI and its impact on BRICS countries: A panel data approach. Transnational Corporations Review, 7(3), 269-278.

Leitão, N. C. (2010). Foreign direct investment: The Canadian experience. International Journal of Economics and Finance, 2(4).

Leitão, N. C., \& Faustino, H. C. (2010). Determinants of foreign direct investment in Portugal. Journal of Applied Business and Economics, 11(3).

M, H Pesaran MH, Y, Shin. (2003). Testing for Unit Roots in Heterogeneous Panels. Journal of Econometrics, 115, 53-74.

Maddala, G. S., \& Wu, S. (1999). A comparative study of unit root tests with panel data and a new simple test. Oxford Bulletin of Economics and statistics, 61(S1), 631-652.

Mahmood, H., Alkhateeb, T. T. Y., \& Furqan, M. (2020). Exports, imports, foreign direct investment and $\mathrm{CO} 2$ emissions in North Africa: Spatial analysis. Energy Reports, 6, 2403-2409.

Mohamed, S. E., \& Sidiropoulos, M. G. (2010). Another look at the determinants of foreign direct investment in MENA countries:
An empirical investigation. Journal of Economic Development, 35(2).

Mukhtarov, S., Aliyev, S., Mikayilov, J. I., Ismayilov, A., \& Rzayev, A. (2020). The FDI-CO2 nexus from the sustainable development perspective: The case of Azerbaijan. International Journal of Sustainable Development \& World Ecology, 1-9.

Narula, R. (2014). The limits of "new" multinational enterprises: Institutions, systems, and "members-only" location advantages. In Cuervo-Cazurra, A., Ramamurti, R. (Eds.), Understanding multinationals from emerging markets (pp. 81-107). Cambridge, England: Cambridge University Press. NBER working paper 13148.

Nunes, C., Oscategui, J., \& Peshchiera, J. (2006). Determinants of FDI in Latin America. Documento De Trabajo, 252.

OECD. (2002). Checklist for Foreign Direct Investment Incentive Policies. Accessed 0ctober 3, 2013 from http://www.oecd.org/ dataoecd/47/51/1959815.pdf

OECD. (2002). Foreign Direct Investment for Development: Maximising Benefits, Minimising Costs. Open Economy Review, 21, 201-219. Accessed April 14, 2010 from http://www.oecd.org/ dataoecd/47/51/1959815.pdf

Persyn, D., \& Westerlund, J. (2008). Errorcorrection-based cointegration tests for panel data. The STATA Journal, 8(2), 232241.

Pesaran, M. H. (2003). Estimation and inference in large heterogenous panels with cross section dependence.

Pesaran, M. H. (2007). A simple panel unit root test in the presence of cross $\square$ section dependence. Journal of Applied Econometrics, 22(2), 265-312.

Pesaran, M. H., \& Smith, R. (1995). Estimating long-run relationships from dynamic 
heterogeneous panels. Journal of Econometrics, 68(1), 79-113.

Pesaran, M. H., \& Smith, R. (1995). Estimating long-run relationships from dynamic heterogeneous panels. Journal of Econometrics, 68(1), 79-113.

Pesaran, M. H., \& Yamagata, T. (2008). Testing slope homogeneity in large panels. Journal of Econometrics, 142(1), 50-93.

Pesaran, M. H., \& T. Yamagata. (2008). Testing slope homogeneity in large panels.

Pesaran, M. H., Ullah, A., \& Yamagata, T. (2008). A bias $\square$ adjusted LM test of error cross $\square$ section independence. The Econometrics Journal, 11(1), 105-127.

Pesaran, M. H., Ullah, A., \& Yamagata, T. (2008). A bias $\square$ adjusted LM test of error cross $\square$ section independence. The Econometrics Journal, 11(1), 105-127.

Pesaran, M. H., Y. Shin, \& R. J. Smith (1999) Bounds Testing approachesto the analysis of long-run relationships, University of Cambridge DAE Working Paper 9907 available on www.econ.cam.ac.uk /faculty/ pesaran.

Rana, R., \& Sharma, M. (2020). Dynamic causality among FDI, economic growth and $\mathrm{CO} 2$ emissions in India with open markets and technology gap. International Journal of Asian Business and Information Management (IJABIM), 11(3), 15-31.

Ranjan, V., \& Agrawal, G. (2011). FDI inflow determinants in BRIC countries: A panel data analysis. International Business Research, 4(4), 255.

Schneider, K. H., \& Matei, I. (2010). Business climate, political risk and FDI in developing countries: Evidence from panel data. International Journal of Economics and Finance, 2(5).
Shahbaz, M., Shahzad, S. J. H., Alam, S., \& Apergis, N. (2018). Globalisation, economic growth and energy consumption in the BRICS region: The importance of asymmetries. The Journal of International Trade \& Economic Development, 27(8), 985-1009.

Smith, R. P. (2000). Estimation and inference with non-stationary panel time-series data (Vol. 7, No. 8).

Swamy PAVB. (1970). Efficient inference in a random coefficient regression model. Econometrica, 38, 311e23.

UNCTAD. (2014). World Investment Report. New York: United Nation.

UNCTAD. (2018). World investment report: Regional investment trend. https://unctad. org/en/PublicationsLibrary/wir2016_en.pdf

Vijayakumar, N., Sridharan, P., \& Rao, K. C. S. (2010). Determinants of FDI in BRICS Countries: A panel analysis. International Journal of Business Science \& Applied Management (IJBSAM), 5(3), 1-13.

Wang, Z., Bui, Q., \& Zhang, B. (2020). The relationship between biomass energy consumption and human development: Empirical evidence from BRICS countries. Energy, 194, 116906.

Wolf, M. (2008). Fixing global finance. John Hopkins Press.

Xu, D., \& Shenkar, O. (2002). Institutional distance and the multinational enterprise. Acad. Manage. Rev., 27(4), 608-618.

Yüksel, S., Dinçer, H., Karakuş, H., \& Ubay, G. G. (2020). The negative effects of carbon emission on FDI: A comparative analysis between E7 and G7 countries. In Handbook of Research on Sustainable Supply Chain Management for the Global Economy (pp. 20-35). IGI Global. 